\title{
EDITORIAL
}

\section{En busca de una mayor eficacia para los planes de igualdad}

\author{
Eva Ma Blázquez Agudo \\ (https://orcid.org/0000-0002-8214-1960) \\ PATRICIA NiETo Rojas \\ (https://orcid.org/0000-0003-3734-3392) \\ DANIEL PÉREZ DEL PRADO \\ (https://orcid.org/0000-0001-7106-6769)
}

doi: https://doi.org/10.20318/femeris.2020.5381

Los planes de igualdad se han convertido en un instrumento esencial en el avance de la igualdad en el ámbito laboral. Sin embargo, desde su incorporación a nuestro ordenamiento jurídico por la LOIMH se han venido observando una serie de barreras que limitan su eficacia desde la perspectiva práctica. Las reformas normativas más recientes (el RDL $6 / 2019$, del que hablaremos más adelante) han pretendido precisamente abordar estos problemas, fortaleciendo esta herramienta jurídica de lucha contra la desigualdad en el ámbito de las condiciones de trabajo.

Teniendo en cuenta el tiempo transcurrido desde su creación y, muy especialmente, estas novedades legislativas, se hacía imprescindible abordar de forma monográfica la situación y perspectivas de este instrumento jurídico en nuestro ordenamiento. De ahí que la Junta Directiva de la AEDTSS decidiera dedicar el Acto Institucional "Igualdad de las Mujeres" 2020 a los planes de igualdad. De esta forma se consolida la apuesta decidida de la AEDTSS por reflexionar y aportar, desde una perspectiva práctica, soluciones a las dificultades que encuentran las mujeres en el ámbito laboral.

El presente número recoge, entre otros, los trabajos resultantes de esta jornada (además de una crónica sobre su desarrollo). En concreto, podrá observar cómo se han abordado los planes de igualdad desde múltiples perspectivas, ya sea en lo que hace a su alcance y contenido, el diagnóstico para su elaboración, ya sea en lo que se refiere a su aplicación y gestión diaria. Mención especial merece el trabajo de la profesora Grau, Premio

*eagudo@der-pr.uc3m.es 
8 de marzo-Igualdad de las mujeres, no solamente por su contenido, sino por sintetizar lo que constituye el nexo común de todas estas aportaciones: su eminente carácter práctico. Así, la profesora Grau reúne en su artículo las principales debilidades ("enemigos") que se detectan en la práctica diaria en lo que hace a la eficacia última de los planes de igualdad.

Por tanto, que se analice cuál es el recorrido del RD Ley 6/2019 un año después parece del todo pertinente, pues, con esta decisión, se extiende la obligación de negociar planes de igualdad a todas las empresas de más cincuenta personas trabajadoras, estableciendo la aplicación paulatina de esta obligación, de modo que:

Las empresas de más de ciento cincuenta personas trabajadoras y hasta doscientas cincuenta personas trabajadoras contarán con un periodo de un año para la aprobación de los planes de igualdad. Las empresas de más de cien y hasta ciento cincuenta personas trabajadoras, dispondrán de un periodo de dos años para la aprobación de los planes de igualdad. Con la nueva redacción dada al art. 45 LOIEMH, la obligación alcanza una entidad mayor, pues, conforme a los datos del DIRCE, son 20.485 las empresas que dan ocupación entre 50 y 249 trabajadores, las cuales emplean al 14.9\% de la población activa en nuestro país. Ahora bien, ni la primera redacción de la LOIEMH ni la dada por el RD Ley 6/2019 solucionan la falta de precisión de las reglas que habrán de aplicarse para medir la dimensión de la plantilla, pues no se determina cuándo debe efectuarse el cómputo, ni cómo se computan los trabajadores temporales y los trabajadores a tiempo parcial, ni qué impacto tienen las fluctuaciones de plantilla que, en un momento dado, sitúen a la empresa de forma sobrevenida en el umbral mínimo -de 51 trabajadores- o por debajo del mismo.

Como certeramente recuerda el profesor Mellado en el artículo publicado en este número, "la LOIEMH nace del convencimiento de que solo una actuación integral que abordase el conjunto de situaciones que sitúan a la mujer en peores condiciones sociales podía contribuir a superar ese estado de cosas; la LOIEMH nace así con esa voluntad de tratamiento integral $y$, al margen de imperfecciones técnicas e insuficiencias, pretendía en el ámbito laboral que se abordasen también en él integralmente los problemas que perpetuaban la desigualdad laboral; para ello actuaba en varias direcciones pero destacaré esencialmente tres: en primer lugar perfeccionaba la tutela antidiscriminatoria; en segundo lugar mejoraba la legislación mediante correcciones en ciertos preceptos legales y, en tercer lugar y sobre todo, introducía la necesidad de negociar medidas de igualdad y, en ciertas empresas, planes de igualdad. La LOIEHM pretendía ser así una ley integral y pretendía que en ese tratamiento integral, el protagonismo en el ámbito laboral lo asumiesen los planes de igualdad que debían ser los que en el ámbito concreto de cada empresa estableciesen el tratamiento laboral integral necesario para garantizar la igualdad, en el convencimiento de que sin esa concreción en el ámbito más reducido, los preceptos legales generales no conseguían desplegar totalmente su función igualitaria”.

Para revertir esta situación, el RD Ley 6/2019 apuesta por la participación de la plantilla en los planes de igualdad, de modo que el diagnóstico ha de ser negociado con la representación legal de los trabajadores, debiendo esperar al desarrollo reglamentario para saber con quién se negocia si en la empresa no se han elegido a estos representantes. Sobre este aspecto es de necesaria consulta el trabajo que ha realizada la profesora 
Domínguez Morales en el monográfico que aquí se presenta. Para la realización de este diagnóstico puede ser sumamente útil la adhesión al servicio puesto en marcha por el Instituto de la Mujer, "Igualdad en la Empresa", en la medida en que desde una instancia independiente se consigue una evaluación externa de la situación y, sin carácter coercitivo, se proponen medidas concretas a adoptar. Durante esta fase habrá que detectar prácticas y cláusulas que puedan encerrar una discriminación indirecta (v. gr. desigual retribución para trabajos de igual valor, construyéndose la diferencia a partir de un factor neutro, como lo es el encuadramiento profesional; desigual retribución para trabajadores contratados temporalmente, cuando el colectivo de trabajadores temporales esté constituido mayoritariamente por mujeres).

Finalmente, el RD Ley reconoce a la representación legal un derecho de información al registro salarial previsto en el artículo 28.2 ET al tiempo que les reconoce una competencia de vigilancia del respeto y aplicación del principio de igualdad de trato y de oportunidades entre mujeres, pudiendo exigir su cumplimiento en sede administrativa o judicial. Y a este respecto, brillantemente recuerda la profesora Selma, en el artículo publicado en este número, lo altamente conveniente es que se cree una comisión de igualdad para la gestión del plan, “"comisión de igualdad” que será la encargada no sólo de valorar los datos estadísticos obtenidos, sino también de proponer las estrategias destinadas a solventar los problemas detectados, comprobar su correcta ejecución, y llegado el caso, plantear su eventual supresión, revisión o mejora, dependiendo de cuál haya sido la evolución de la situación en la empresa".

Aunque ahora aparece que todas las instituciones laborales están trabajando para dar una respuesta integral a los efectos derivados del COVID-19, también sería necesario que la igualdad de género no salga de la agenda pública y se cumplan los compromisos políticos que están detrás del desarrollo reglamentario de los planes de igualdad, especialmente porque su materialización conlleva la creación de registro de planes de igualdad, lo cual parece especialmente pertinente de cara a la obtención de la información más transparente en relación al estado de los planes. 